\title{
A ADOÇÃO DA SUSTENTABILIDADE DOS GRUPOS TRANSNACIONAIS, E OS ESFORÇOS DA OCDE
}

\author{
Silvia Elena B. Saborita * \\ Edson Ricardo Saleme **
}

\section{Resumo:}

Este trabalho busca enforcar os esforços de empresas transnacionais no exercício de atividades que possam comprometer a biodiversidade das regiões que atuam. É possível afirmar que com a adoção de boas práticas incorporadas no desempenho de atividades propiciem um ambiente adequado. A existência de norma que exija a produção de planos e projetos prévios em prol da sustentabilidade e o licenciamento ambiental devem buscar a redução de externalidades. Portanto, as exigências internacionais produzidas pela OCDE devem ser observadas para o desempenho sustentável de atividades empresariais. Este trabalho empregará o método hipotético dedutivo e a metodologia será a bibliográfica e documental.

\section{Palavras-chave:}

OCDE; boas práticas empresariais; licença; sustentabilidade; externalidades

\section{THE ADOPTION OF THE SUSTAINABILITY OF TRANSNATIONAL GROUPS, AND THE OECD'S EFFORTS}

\begin{abstract}
:
This paper aims to focus the efforts of transnational companies in order to get environmental licence of activities that could compromise the biodiversity. It is possible to affirm that with the adoption of good practices incorporated in the performance of activities could provide an adequate environment. The existence of a standard that requires the production of previous plans and projects for sustainability and environmental licensing should reduce externalities. Therefore, the international requirements produced by the OECD must be observed for the sustainable performance. This work will use the hypothetical deductive method and the methodology will be the bibliographical and documentary.
\end{abstract}

\footnotetext{
*Doutoranda em Direito Ambiental Internacional pela Universidade Católica de Santos; mestre em Direito Ambiental pela Unisantos. Graduada em Direito e Professor de Direito da Universidade Paulista, Fundação Armando Álvares Penteado e membro ativo da ONG Centro Vivo de São Paulo. Advogada em São Paulo. End. Av. Conselheiro Nébias, 589/595 - Santos/SP; E-mail: silvia.saborita@gmail.com

**Pós-doutorando pela Universidade Federal de Santa Catarina. Doutor em Direito do Estado pela Universidade de São Paulo. Graduado pela PUC-SP. Professor do Curso Stricto Sensu em Direito Ambiental Internacional da Unisantos; professor da Escola Superior de Advocacia. Consultor do IBAMA. Advogado em São Paulo. End. Av. Conselheiro Nébias, 589/595 - Santos/SP. E-mail: ricasal@unisantos.br
} 


\section{Keywords:}

OECD; good environmental practices; environmental licence; sustentability; externalities

\section{Introdução}

O direito internacional do meio ambiente discute muito a questão dos impactos ambientais e a repercussão deles no mundo atual gerado por pessoas naturais ou artificiais e como isso pode afetar o futuro das presentes e futuras gerações. Durante o século XX é inegável a verificação do desnivelamento entre os países, o que trouxe aumento das ocorrências gravosas em termos de impacto, ou seja, além de se criar condições desfavoráveis de vida, observa-se também deslocamento de pessoas com vistas a melhores condições de emprego e de vida isso sem se referir ao ambiente inadequado que práticas usurpadoras podem conduzir o país, tal como excessiva degradação do ambiente e lançamento contínuo de resíduos. Diante desse quadro, existem algumas opções possíveis. Entre elas se pode referir ao beneficiamento do ambiente local, por meio de boas práticas e normas que as viabilizem e como se pode adotá-las sem afugentar empresas criadoras de empregos e que desenvolvem a economia local.

Empresas transnacionais exercem tamanha influência que inegavelmente transcende a economia. É possível afirmar que interfere em governos e até mesmo em sua relação com outros Estados. É possível verificar a expansão dessas empresas a partir da Segunda Guerra Mundial, quando decidiram migrar de seus países de origem para outros locais em que pudessem desenvolver suas atividades pelo mundo. Até pouco tempo atrás tais empresas eram denominadas simplesmente por multinacionais. Contudo, nota-se que essa designação caiu em desuso, sobretudo por denotar uma idéia de uma empresa que possui diversas nacionalidades. As empresas que venham a desempenhar suas atividades em outros países recebem a designação mais adequada de transnacionais, uma vez que possuem sede em determinado país e desempenham em outros suas atividades.

As transnacionais estão inexoravelmente conectadas à globalização da produção, em que um único produto pode ter diversas origens. Frequentemente observa-se que a montagem é efetivada em determinada localidade do mundo. Esse fluxo produtivo visa unicamente 
verticalizar os lucros. Diminui invariavelmente os custos e essas empresas se consolidam no mercado como empresas que estão diante do desafio de buscar boas colocações em termos de competitividade internacional. Diante desse quadro que se pode observar o quanto as empresas multinacionais, nos últimos anos, ganharam poder econômico e político e são fundamentais como agentes de mudanças. Muitas delas deveriam ser em prol da sociedade que atuam, por meio de práticas sustentáveis e a incorporação de ações responsáveis e adequadas nas diversas esferas que atuam. As boas práticas sociais, políticas e ambientais não eram sequer cogitadas por essas empresas até pouco tempo atrás. Porém, a realidade apontou para o fato de que essas mudanças seriam fundamentais para a própria manutenção da atividade e, assim, deveriam implementar boas práticas em sua conduta empresarial.

Neste trabalho se verificará como as empresas transnacionais atuam e como as boas práticas podem ser incorporadas em seu dia-a-dia para que venham a desempenhar atitudes que também propiciem um ambiente adequado. Não basta a existência de uma norma que exija a produção de planos e projetos prévios em prol de uma suposta busca pela sustentabilidade. A produção diária e sua prática reiterada é que deve ser no sentido de se adotar fórmulas que venham a produzir cada vez menos externalidades e reduzir ao máximo as respectivas emissões.

As questões que aqui se colocam se resumem basicamente nas seguintes: como estão atuando as empresas transnacionais e quais são suas práticas atentatórias à sustentabilidade? É possível que elas venham a incorporar boas práticas diante da realidade que mais e mais demonstra a necessidade de proteção do ambiente e de grupos vulneráveis? É possível a criação de instrumento certo para identificar e compartilhar o valor das boas práticas empresariais que possam contribuir concretamente com a busca pelo melhor desempenho ambiental das atividades humanas?

Considerando as possíveis hipóteses diante da realidade de que, em um primeiro momento, podem não ter um rol de práticas adequadas para desempenho em determinado país. Ao contrário, o que efetivamente ocorre é um rol de benefícios e incentivos, tais como isenção de tributos e taxas, viabilidade de se ceder localidade; enfiam são ofertados benefícios para que se mantenham naquele local. Tudo em prol da atração de novos investimentos estrangeiros e busca pela manutenção daquela atividade também garantir a permanência das 
empresas. Não se pode negar que elas geram grande número de postos de trabalho, garantidos pela concentração de grande capital que a empresa transnacional traz para o novo território, isso sem contar com a presença também atrai outros tipos de empresas que com ela desempenham determinadas atividades, a exemplo das montadoras.

As boas práticas não são reveladas, a princípio. A empresa traz consigo um rol de necessidades, ao contrário, que os estados receptores não tardam a cumprir, se isso realmente for possível. O que se observa, entretanto, é que o desempenho da atividade por certo período de tempo pode levar a adoção paulatina de práticas possivelmente sustentáveis.

A metodologia aqui empregada será em grande parte a bibliográfica e documental. $\mathrm{O}$ método, como já observado acima, será o hipotético-dedutivo, no sentido de que as questões propostas poderão ou não ser confirmadas diante da pesquisa efetuada, que também se baseou em casos reais que atualmente estão ocorrendo no Planeta.

Grande parte das empresas transnacionais é oriunda de países desenvolvidos e com relevante capital no mercado. O que se nota nos fóruns internacionais é a constante reclamação de que as práticas sustentáveis seguidas em seus países de origem não são sequer cogitadas na exploração ou mesmo desempenho de atividades em outros países. Aqui se observará se existe a possibilidade de criação de algo que essas empresas reconheçam como importante a ser observado em termos de sustentabilidade.

Aqui, certamente, será observada apenas pequena parcela do tema já que o assunto engloba situações complexas e que uma singela análise não será suficiente para propor eventuais soluções. O que talvez seja possível retratar é como o mundo vem tratadndo as questões vertente e como as agendas internacionais se ocupam desse tema extremamente relevante na atualidade.

\section{1 - A globalização e seu impacto ecológico}

A globalização é entendida como um fenômeno substancialmente econômico com profundos impactos comerciais. Seu aspecto mais peculiar é a abertura de mercados, 
desenvolvimento do comércio internacional e movimentação de capital. Há também uma dimensão relacionada à tecnologia, pois o intercambio tecnológico é essencial para que a economia entre os países possa melhor se desenvolver. No que concerne ao aspecto ecológico a questão pode ter alguma relevância em determinados blocos econômicos. Porém, diante das manifestações do líder do país que mais realiza negócios no mundo parece que a questão ambiental tem sido observada como algo a se considerar de forma não muito contundente.

Anthony Giddens (1990), que se dedicou ao tema, entende ser a globalização uma intensificação de relações sociais em uma escala mundial, que venha a conectar localidades distantes de tal forma que acontecimentos locais sejam modelados por eventos que venham a ocorrer em locais distantes ou vice e versa.

Há também uma diferença feita por Mattos (2010) no que concerne ao localismo globalizado e ao globalismo localizado. O primeiro consiste na atividade empresarial bem sucedida que influencia onde comercializa seus produtos, bem como a transformação do idioma inglês, por exemplo, para além dos países que o tem como idioma local. O Globalismo localizado consiste, ao contrário, em impacto relativo a implantação de práticas transnacionais em ambiente local, a exemplo de práticas implementadas para atender interesses locais.

Roberto Caparroz (2012) afirma que, no início da implementação da globalização, todos criam que ganhariam muito com ela, pois estaria livre o acesso a mercados e o livre fluxo de bens e serviços. Isso traria benefício tanto para os países ricos como para os em desenvolvimento. Isso porque os primeiros teriam bilhões de novos consumidores potenciais e os outros receberiam investimentos e teriam acesso a novas tecnologias.

Outro aspecto sublinhado pelo autor é que a globalização, altamente concentrada em questões de liberdade de capital, estabelece também certa interdependência entre os Estados envolvidos, de certa forma enfraquece o conceito de Estado-nação que, no passado, foi decisivo para as decisões políticas desses estados. 
Diante desses fatores os países que ingressam nas práticas globalizantes não tiveram tantas vantagens quanto imaginava. O comércio internacional traz consequiências nem tanto positivas para a pulverização do mercado. As empresas transnacionais ficaram mais fortes e práticas anticompetitivas são consideradas normais. Isso sem olvidar que o ambiente e práticas sustentáveis também parecem se tornar distantes.

Esta tese é corroborada por José Avelãs Nunes (2003) ao afirmar que a globalização teria como principais protagonistas os grandes conglomerados transnacionais orientados por uma estratégia planetária. Nesse sentido, trata-se de um fenômeno complexo que se manifesta em múltiplos aspectos, mas que tem no terreno econômico sua estratégica projeção. Esse mercado mundial unificado apóia-se no desenvolvimento dos transportes e da tecnologia de informação tornando possível controlar estruturas produtivas em varias partes do globo desde sua matriz em temporal, de qualquer ponto do mundo.

O desenvolvimento dos países rumo à globalização, portanto, incorpora esse conjunto de consequências, nem sempre positivas. Esses grupos transnacionais que nas palavras de Flávio José Rocha da Silva (2018) estão presentes em praticamente todos os setores da economia. Nos últimos anos, segundo o autor, elas têm enveredado por novos campos como mercado de água e de economia verde. Seu objetivo é a busca de novos territórios com mão-de-obra barata, acesso a matéria prima de boa qualidade e controle de preços, bem como venda de seus produtos à comunidade local. Desta forma garantem hegemonia localmente.

Adiante o autor segue afirmando que os governos, alicerçados na crença de que a chegada dessas empresas e empreendimentos trará ganho efetivo e melhoria das condições de vida local. Desconhecem, entretanto, que "a chegada das transnacionais para sua localidade é uma conseqüência do fato de que a pilhagem ao patrimônio natural na comunidade onde estavam instaladas previamente já ter atingido seu ponto máximo, obrigando-as a procurar novo espaço.” 
Nesse quadro de exploração comercial é comum que essas empresas passem a lutar por normas mais brandas que gerem menor oneração e estejam de acordo com seus interesses preponderantes: a de explorar os recursos minerais a menor custo e com trabalhadores que possam realizar suas tarefas com o menor dispêndio de recursos possível, a fím de que atinjam maior lucratividade.

\section{2 - Impactos socioambientais nocivos}

Em 1992, o Brasil foi sede da Conferência das Nações Unidas para o Meio Ambiente e Desenvolvimento (ECO-92). Nesta reunião diversos interesses eram discutidos entre os Estados envolvidos. Nela, segundo entendimento de Ana Lucia Guedes (2003) os países industrializados deram maior atenção a temas como a destruição da camada de ozônio, aquecimento global, chuva ácida e no desflorestamento. Os países em desenvolvimento estavam mais preocupados com a proteção ambiental e o desenvolvimento econômico.

A globalização não é um processo recente. É uma nova face do capital internacional, conforme afirmou Rosenau (2000). É fato recente que as forças sociais e políticas que se lhe opõem estarem mais organizadas agora que antes. Essas forcas políticas podem estar em extremos opostos, dependendo do que se ofereça e de quanto sejam esclarecidas acerca do que pode ou não trazer o desenvolvimento de determinados negócios em território nacional. Esse conjunto de fatores depende da honestidade das informações prestadas quanto ao nível de impacto que a atividade pode gerar no território.

Diante desse quadro que parece irreversível Alaôr Café Alves (2005, 297-357) esclarece que diante desses segmentos, sobretudo os que professam a permanência de empresas que desenvolvam atividades ambientalmente impactantes, há também representantes compromissados com as forças democráticas participativas. Na sociedade civil, portanto, onde existiam apenas forcas em prol de atividades destinadas ao lucro, uma dimensão de autêntico interesse público que não se identifica com a estatal. 
Isso indica que o poder de dominação política exercido pelas transnacionais. Influenciam as esferas governamentais e a população impactada busca mecanismos de defesa que se encontram fora do Estado. A criação de organizações não-governamentais parecia ser a solução encontrada para a defesa de interesses coletivos e difusos relacionados ao ambiente. Convém mencionar, entretanto, que não obstante a fachada de defensora de interesses sociais e sociais é possível, de outra forma, que venham a defender os interesses das próprias transnacionais. Isso é visível em algumas entidades e muito simples em se constatar pelo fato de que muitos interesses comerciais convergem para a esfera de interesses difusos e nesse aglomerado de "interesses" aquele relacionado ao das empresas seja considerado o mais adequado.

Importante também mencionar a questão da defesa da cultura tradicional, mormente a dos povos pertencentes à Amazônia legal. Essas populações têm recorrido à atuação do Ministério Público para que seu interesse seja preservado em face da voracidade de empresas preocupadas exclusivamente com seu próprio lucro, sem a observância de que ali vivem comunidades tradicionais e que sobrevivem dessa atividade. Isso vem ao encontro do que aqui se discute: o capital está submetendo cada vez mais o modelo de progresso para a implementação da chamada "Economia Verde", como sendo aquela cuja tecnologia seria possivelmente algo enquadrável como mitigadora e que sua atuação estaria agindo nos moldes do que se considera eco-friendly. ${ }^{3}$

Há diversas entidades que se denominam auto-sustentáveis e que estariam em sintonia com o chamado "desenvolvimento sustentável" que buscam mascarar sua atuação predadora como forma de trazer benefícios econômicos com a multiplicação de empregos. $\mathrm{Na}$ verdade sua atuação pode trazer malefícios irreversíveis, como será visto no próximo capítulo que será dedicado a ação predadora. Há diversos termos utilizados para mascarar ações de

\footnotetext{
3 A expansão das monoculturas na região dos babaçuais e da pecuária tem ameaçado o trabalho das quebradeiras de coco do Piauí, Tocantins, Maranhão e Pará. Essas pessoas e famílias que vivem do babaçu apelaram em prol de norma que possa garantir o livre acesso a essas palmeiras, mesmo quando inseridas em propriedades privadas. Isso Também incluiriam restrições à derrubada da planta. A alteração do uso do fruto foi reunião das quebradeiras de coco babaçu como Ministério Público Federal. Disponível em < http://www.mpf.mp.br/to/sala-de-imprensa/noticias-to/mpf-to-e-movimento-das-quebradeiras-de-cocobabacu-realizam-reuniao-1>, acesso em 05.05.2018.
} 
grandes empreendimentos e evitar possíveis posições contrárias de grupos sociais organizados que possam se opor a instalação dessas atividades usurpadoras do ambiente.

A atuação das empresas multinacionais parece estar mais voltada a interesses exclusivamente econômicos. Contudo, é possível que entidades do terceiro setor possam influenciar positivamente no sentido de que apoiar ações em prol da sustentabilidade e buscar soluções a determinados problemas das empresas que envolvam produtos e processos, pode viabilizar ações que tratem de desempenho e aproveitamento de resíduos, por exemplo

Pode-se inclusive mencionar as práticas de gestão que sugerem ações de melhoria e monitora a eficácia dessas ações, por diversas formas. Viabiliza uma análise integrada das diversas dimensões, a fim de que o gestor possa tomar a decisão mais acertada em todos os termos. ${ }^{4}$

Atualmente se está buscando um toque de equilíbrio para que haja uma possível fórmula sustentável. Não obstante existam mecanismos controladores da atuação empresarial, tal como o licenciamento e outros que exigem a demonstração de intervenções para redução de impacto, na verdade, observa-se grande pressão por diversos setores estatais para que os mecanismos não sejam inibidores da atividade empresarial e suas externalidades, sejam elas quais forem, sejam reduzidas para que as atividades possam ser realizadas de forma mais dinâmica.

\section{3 - Práticas empresariais e a proteção do ambiente}

\footnotetext{
${ }^{4}$ Aqui se faz referência a uma empresa associada de outras empresas européias, a sustentare, cujo intuito é "ir além das dimensões Financeira, Ambiental e Social. Expandimos o conceito do Triple Bottom Line, incluíndo dimensões como Pessoas, Processos, Qualidade e Saúde, além de outras, que influenciam no Desempenho Organizacional Sustentável da Empresa, visando uma gestão de excelência, com resultados crescentes.' Disponível em http://www.sdos.com.br/?gclid=Cj0KCQjwz7rXBRD9ARIsABfB180SL4Lwx1 go2M4TUAmE4330maa1auuMo FSsftf7uuKNFhl9bH099-saAkIKEALw_wcB>. Acesso em 06/05/2018.

Rev. de Direito, Economia e Desenvolvimento Sustentável | e-ISSN: 2526-0057| Goiânia | v. 5 | n. 1 | p. 23-38| 
Efetivamente a situação geralmente é contrária aos interesses difusos internos já que pode conflitar com a proteção socioambiental local e outros interesses internos da sociedade. É também perfeitamente possível que haja, por parte do próprio poder público, medidas que proporcionem facilidades para implementação de atividades que possam ficar mais inclinada à possíveis danos em território nacional e que possam gerar danos.

Acselrad e Bezerra (2013) alertam que é perfeitamente possível que uma empresa de caráter transnacional venha a ser instalada em uma comunidade e ai obtenha facilidades. Nesse caso é também observado que se estabeleçam mudanças em determinadas normas para a diminuição ou mesmo exclusão da proteção nos campos jurídicos, político e fiscal para que a atividade seja efetivada. Desta forma, os chamados "novos investimentos" podem ser acolhidos com a garantia de que não sofrerão possíveis perdas econômicas advindas de conflitos com as comunidades locais atingidas de forma negativa.

Antes das conferências ambientais, por exemplo, a de Estocolomo, em 1972, a proteção ao meio ambiente era realizada de maneira pouco perceptível mundo afora, sobretudo para permitir a exploração de atividades que poderiam ser consideradas impactantes ao ambiente. Aliás, o Brasil e mais 66 países se opuseram a sua assinatura pois já estavam a par das obstruções que o ambiente pode causar à atividade empresarial. É recente a necessidade de que antes de se explorar a atividade sejam observadas as atividades que merecem restrições e que sejam efetivamente fiscalizadas pelo poder público em face de possíveis transgressões ao ambiente.

Diante dessa situação em que o Estado pouco se posicionava em termos normativos é possível afirmar o constatado por Maurício Ribeiro (1999) no sentido de que:

\footnotetext{
"Até meados do século passado, o conteúdo dos sistemas normativos das sociedades ocidentais fundava-se em bases sólidas. As revoluções do século XVIII que marcaram, na Europa continental, a ascensão da burguesia, consolidaram uma série de valores como a autonomia da vontade, o pacta sunt servanda, o respeito aos direitos adquiridos, a pessoalidade da responsabilidade, a auto-regulação dos mercados e o seu corolário, a não-intervenção estatal no domínio econômico. Tais valores, hierarquicamente organizados, constituíram o cerne da ideologia liberal.”
} 
O Brasil, após a década de 1980, diante das pressões internacionais e de sua adesão à Conferência de Estocolmo 5 e outros atos internacionais em prol do ambiente publicou a Lei da Política Nacional do Meio Ambiente (Lei 6.938/1981), que introduziu diversas normas em prol do ambiente, inclusive sanções aos que desrespeitassem alguns dispositivos. Importante mencionar que a Constituição Federal de 1988 trouxe capítulo próprio para a defesa do ambiente e procedimentos que deveriam ser observados para a condução da política nacional relacionada a ele. Outra norma que merece elogios é a Lei que dispõe sobre sanções penais e administrativas para atos lesivos ao meio ambiente (Lei 9.605/98).

Diante da complexidade das relações sociais houve um incremento das normas em todos os sentidos. Ribeiro (1999) ainda esclarece que:

\begin{abstract}
"A crescente complexidade das sociedades, sobretudo a partir da segunda metade do século XIX, implicou em vertigionoso aumento da atividade legislativa. Não é por acaso que, já no principio do século XX, juristas como Leon Duguit e Gaston Morin falavam na revolta dos fato contra os Códigos...no princípio da década de 30, juristas do porte de Carnelutti assinalavam o fenômeno da inflação legislativa, que tornava a atividade adjudicativa mais complicada."
\end{abstract}

Destarte, a atividade legislativa passou a legitimar uma série de atos que possam interessar a coletividade e que teriam repercussão social. É possível afirmar que o Direito se dedicou a áreas cada vez mais diversas e passou a constituir o que mais adiante foi denominado legislação extravagante.

A necessidade de criação de uma entidade para cuidar do ambiente fez com que se consolidasse o que antes teria aspecto de um simples órgão de assessoramento. Pelo histórico, sem contar com denominações precedentes, em 1990, criou-se o Ministério do Meio Ambiente (2018), posteriormente transformado em Secretaria do Meio Ambiente. Em 1993, transformou-se em Ministério do Meio Ambiente e da Amazônia Legal e, em 1995, designouse o órgão como Ministério do Meio Ambiente, dos Recursos Hídricos e da Amazônia Legal, adotando, posteriormente, o nome de Ministério do Desenvolvimento Urbano e do Meio Ambiente. Desde 1999 mantém-se o Ministério do Meio Ambiente.

\footnotetext{
${ }^{5}$ O Brasil junto com 66 países se opuseram a firmar a Conferência de Estocolmo alegando que esse documento seria um artifício para que os países desenvolvidos excluíssem os em desenvolvimento do comércio internacional.
} 
As normas, a partir de 1980, demonstraram nítida preocupação com o meio ambiente como um todo, desde a criação de um sistema permeado por vários entes (Lei da Política Nacional do Meio Ambiente) até a previsão de mecanismos jurídicos para o combate e a repressão de atos tendentes a degradar o meio ambiente, seja por meio de ações concretas (ao possibilitar a utilização da Ação Civil Pública para a defesa do meio ambiente), seja por meio de proibições abstratas gerais, ao prescrever que práticas atentatórias ao meio ambiente serão objeto de penalização criminal e administrativa, inclusive às pessoas jurídicas (Lei 9.605/98).

No mesmo viés de proteção global e diluída, a Constituição Federal de 1988 dedicou um capítulo exclusivamente ao meio ambiente (Capítulo VI), destacando o direito de todos ao meio ambiente ecologicamente equilibrado, bem de uso comum do povo e indispensável à sadia qualidade de vida (artigo 225). Este artigo trouxe grande parte das aspirações dos grupos ambientalistas em termos protetivos, sem falar que trouxe o importante conceito de "bem ambiental", como fórmula de proteção que atinge bens públicos e privados, sem exceção.

As boas práticas podem tardar. Porém, as externalidades devem ser mitigadas e o EIA deve demonstrar nos pedidos de Licença Ambiental o grau de esforços da empresa em mitigar o que a empresa pode produzir em externalidades. A empresa, contudo, traz um rol de necessidades contrárias às práticas sustentáveis. O que se observa, entretanto, é que o desempenho da atividade por certo período de tempo pode levar a adoção paulatina de práticas possivelmente sustentáveis.

As empresas transnacionais são relevantes para o desenvolvimento dos países em que se inserem. Contudo, podem trazer efeitos nocivos. Não há como negar a influência nos sistemas regulatórios, sobretudo atualmente em que se cogita a prática de redação de medidas provisórias por setores interessados em sua publicação. Isto estabelece prática que retira dos instrumentos jurídicos a promoção do bem estar e do atendimento do interesse coletivo. Isto pode atingir diversos ramos jurídicos.

\section{4 - Possibilidades de práticas sustentáveis e o papel da OCDE}


A compreensão da contribuição inegável das transnacionais para o desenvolvimento e de seus impactos adversos, precisam ser ponderados por meio da compreensão do fenômeno do desenvolvimento como um direito humano e fundamental, nas palavras de Hastraiter e Villatores (2014, 45-70).

A busca por um equilíbrio entre a promoção de atividades empresariais pelas transnacionais e os impactos negativos que se possam trazer desenvolvimento econômico é um dos grandes desafios contemporâneos, e um dos fundamentos para a criação das Diretrizes da OCDE (Organização para a Cooperação Econômica e o Desenvolvimento). Esta organização foi inicialmente fundada por países desenvolvidos e o Brasil está interessado em ingressar nessa organização (2019).

As diretrizes da OCDE (2019), que o Brasil está cada vez mais interessado em ingressar, em muito contribuem para o esclarecimento dos pontos que devem ser objeto de atenção e assim assegurar a prevalência dos direitos humanos em seu território, cabendo às empresas observar as normativas internas. No entanto, estabelecem que ainda que o Estado no qual estejam instaladas falhe na promoção dos direitos humanos, as empresas transnacionais devem observar os padrões internacionais em sua máxima extensão.

Entre as diretivas da OCDE está consignado que as empresas devem levar em considerações e assim contribuir com o progresso econômico, ambiental e social com vistas ao cumprimento do desenvolvimento sustentável. Entre as 15 diretivas está a indicação de que as empresas devem evitar se envolver com políticas que possam ser contrárias as atuações positivas ali indicadas.

Como esclareceu o Ministério das Relações Exteriores (2018), a OCDE é formada por 35 países desenvolvidos. A cooperação do Brasil com esta Organização iniciou-se na década de 1990. Nos últimos anos a Organização estreitou contatos com cinco países emergentes selecionados (África do Sul, Brasil, China, Índia e Indonésia). São chamados chamados "Key Partners". Hoje, praticamente, todos os Ministérios e muitos órgãos da administração pública federal e estadual no Brasil estão, de alguma forma, envolvidos na cooperação com a Organização. O Governo brasileiro já aderiu a 26 Recomendações e outros instrumentos da Organização. 
Observa-se que o Brasil já avançou em direção ao cumprimento das normas estabelecidas por essa Organização, pois é fundamental que suas normas sejam aplicadas a fim de coibir práticas que possam prejudicar o interesse das presentes e futuras gerações, tal como o desenvolvimento sustentável. O ambiente, apesar de suas regras consideradas muitas vezes árduas, não tem sido obstáculo para a construção de grandes empreendimentos mesmo de ordem nacional.

As empresas transnacionais tem buscado em países como a China e India o local adequada para a expansão de suas atividades mais impactantes. O Brasil deve definir sua posição aderindo ou não. A verdade é que grande parte de seus ministérios e órgãos públicos já seguem diversas diretivas da Organização e dela já buscam apoio.

\section{Considerações finais}

O objetivo deste trabalho é a análise das boas práticas efetivadas por empresas que ingressam no território estrangeiro atraída por diversos fatores que podem ir desde ofertas criadas pelo próprio país que podem envolver redução de custos com impostos e taxas ou mesmo a oferta de locais para desempenho de funções. É certo que empresa geralmente traz uma relação de necessidades que os estados receptores deveriam atender. Por outro lado, no início, não se incluem obstáculos que possam repelir a consideração de que aquele território seja realmente atrativo para o desenvolvimento do negócio.

Nem sempre essas boas práticas são visíveis. Os mecanismos impostos pela Lei $\mathrm{n}^{\circ}$ 6.938, de 1981, podem parecer, inicialmente, severos. Contudo, os órgãos ambientais, em suas diversas análises, observam o Zoneamento Ecológico Econômico, necessidades sociais da região, entre outros fatores que não deveriam influenciar em uma decisão estritamente de cunho ambiental.

A determinação legal é clara e atualmente os mecanismos impostos por meio de transmissão de dados via digital distanciam o requerente do órgão ambiental. A relação é cada 
vez mais impessoal, o que torna o ato de licenciamento puramente técnica. Porém, os grandes empreendimento acabam tendo como protagonistas órgãos estatais como prefeituras, órgãos da administração direta ou indireta.

A análise impessoal dos diversos órgãos do Sisnama é fundamental para que as práticas das empresas transnacionais sejam efetivamente adotadas. Isso não ocorre em países africanos, em que sequer existem autoridades licenciadoras, a exemplo da Nigéria e outros que se exploram recursos do petróleo. Todos os países adotam práticas relacionadas com a sustentabilidade ambiental, sobretudo os que assinaram a Conferência de Estocolmo e os demais atos internacionais subsequentes em prol da salvaguarda da biodiversidade.

As empresas são geralmente oriundas de países desenvolvidos e possuem considerável capital, que decidem trazer para países menos desenvolvidos, por ofertar condições vantajosas para o desempenho de suas atividades e poder ali realizar atividades variadas. É possível que o baixo custo do país e o valor dos salários sejam fatores atrativos para a empresa. Porém, esses fatores nem sempre auxiliam determinadas necessidades internas.

A atuação das empresas multinacionais não está totalmente voltada a interesses exclusivamente econômicos. Sua atuação pode prever práticas de gestão que venham a contemplar ações de melhoria em dimensões diversas: financeira, laboral e também ambiental. O terceiro setor, com suas novas tecnologias, têm auxiliado essas empresas a estabelecer uma análise integrada das diversas dimensões, a fim de que o gestor possa tomar a decisão adequada em todas as esferas.

Diante desse quadro que pode parecer impactante para o futuro de grande parte dos países no globo observa-se que a OCDE vem a ser a organização internacional que está preocupada e busca soluções completas para que não haja desvantagem para o país receptor. O Brasil está considerando ingressar, sobretudo após o ingresso do governo que o dirige atualmente e, diante das eleições a definição deverá ser dada oportunamente, por quem Rev. de Direito, Economia e Desenvolvimento Sustentável | e-ISSN: 2526-0057| Goiânia| v. 5 | n. 1 | p. 23-38| 
assumir a Presidência e assim optar para conduzir os rumos do país e receber as empresas transnacionais.

\section{Referências}

AVELAS NUNES, Antonio José. Neoliberalismo e direitos humanos. Rio de Janeiro: Renovar, 2003, p. 71 a 76.

BRASIL. Ministério do Meio Ambiente (MMA). Histórico institucional. http://www.mma.gov.br/o-ministerio/historico-institucional>. Disponível em 06/05/2018.

BRASIL. Ministério das Relações Exteriores (MRE). Organização para a Cooperação e Desenvolvimento Econômico - OCDE. <http://www.itamaraty.gov.br/pt-BR/politicaexterna/diplomacia-economica-comercial-e-financeira/15584-o-brasil-e-a-ocde〉. Disponível em 06/05/2019.

CAPARROZ, Roberto, Comércio internacional. São Paulo: Ed. Saraiva, 2012.

CAFFÉ ALVES, Alaôr. Fundamentos do direito e meio ambiente. In: Philliphi Jr \& Café Alves, A. (orgs.). Curso Interdisciplonar de Direito Ambiental. Barueri: Manole, 2005, p. 297-357.

GUEDES, Ana Lúcia. Empresas transnacionais e questões ambientais: a abordagem do realismo crítico. Rev. Sociol. Polit. no.20 Curitiba June 2003.

GUIDDENS, Anthony. The Consequences of Modernity. Standford University Press. 1990.

MATTOS, As implicações do localismo globalizado sobre a concepção de pessoa.Comunicação \& Informação, v. 13, n.1: p. 25-34 - jan./jul. 2010.

OCDE. OECD Guidelines for Multinational Enterprises - 2011 Edition. Disponível em: <http://www.oecd.org/daf/inv/mne/48004323.pdf>. Acesso em 06/04/2019. 
RIBEIRO, M.P. O direito contemporâneo e a metodologia do ensino do direito. In Direito Global. Org. SUNDFELD, C.A e VIEIRA O.V. Direito global. São Paulo: Max Limonad, 1999, p. 93-106.

ROSENAU, J. N. 2000. A cidadania em uma ordem mundial em mutação. In: Rosenau, J. N. \& Czempiel, O. (orgs.). Governança sem governo: ordem e transformações na política mundial. Brasília: UnB/Imprensa Oficial do Estado de S.Paulo.

VILLATORE, Marco Antônio César e HASTREITER, Michele Alessandra. As diretrizes da OCDE para empresas transnacionais e o direito do trabalho: a pessoa humana como prioridade na busca pelo desenvolvimento. REVISTA DO DIREITO PÚBLICO, Londrina, v.9, n.3, p.45-70, set./dez.2014. Pg. 45 a 70. 